\title{
INDICADORES ECONÔMICOS
}

\begin{tabular}{|c|c|c|c|c|c|c|c|}
\hline \multicolumn{8}{|c|}{ Índices de Preços } \\
\hline \multicolumn{2}{|c|}{ Período } & Mencal & Noano & Em 12 & Momal 1 & Nono & Em 12 \\
\hline \multirow{12}{*}{2010} & Jan. & 1,34 & 1,34 & 4,56 & 0,75 & 0,75 & 4,59 \\
\hline & Fev. & 0,74 & 2,09 & 5,05 & 0,78 & 1,54 & 4,83 \\
\hline & Mar. & 0,34 & 2,44 & 4,98 & 0,52 & 2,06 & 5,17 \\
\hline & Abr. & 0,39 & 2,84 & 5,07 & 0,57 & 2,65 & 5,26 \\
\hline & Mai. & 0,22 & 3,06 & 4,95 & 0,43 & 3,09 & 5,22 \\
\hline & Jun. & 0,04 & 3,10 & 4,86 & 0,00 & 3,09 & 4,84 \\
\hline & Jul. & 0,17 & 3,28 & 4,69 & 0,01 & 3,10 & 4,60 \\
\hline & Ago. & 0,17 & 3,45 & 4,37 & 0,04 & 3,14 & 4,49 \\
\hline & Set. & 0,53 & 4,00 & 4,75 & 0,45 & 3,60 & 4,70 \\
\hline & Out. & 1,04 & 5,08 & 5,58 & 0,75 & 4,38 & 5,20 \\
\hline & Nov. & 0,72 & 5,84 & 6,03 & 0,83 & 5,25 & 4,63 \\
\hline & Dez. & 0,54 & 6,41 & 6,41 & 0,63 & 5,91 & 5,91 \\
\hline \multirow{12}{*}{2011} & Jan. & 1,15 & 1,15 & 6,21 & 0,83 & 0,83 & 5,99 \\
\hline & Fev. & 0,60 & 1,76 & 6,07 & 0,80 & 1,64 & 6,01 \\
\hline & Mar. & 0,35 & 2,11 & 6,08 & 0,79 & 2,44 & 6,30 \\
\hline & Abr. & 0,70 & 2,83 & 6,40 & 0,77 & 3,23 & 6,51 \\
\hline & Mai. & 0,31 & 3,15 & 6,50 & 0,47 & 3,71 & 6,55 \\
\hline & Jun. & 0,01 & 3,16 & 6,47 & 0,15 & 3,87 & 6,71 \\
\hline & Jul. & 0,30 & 3,47 & 6,61 & 0,16 & 4,04 & 6,87 \\
\hline & Ago. & 0,39 & 3,87 & 6,84 & 0,37 & 4,42 & 7,23 \\
\hline & Set. & 0,25 & 4,13 & 6,54 & 0,53 & 4,97 & 7,31 \\
\hline & Out. & 0,39 & 4,53 & 5,86 & 0,43 & 5,43 & 6,97 \\
\hline & Nov. & 0,60 & 5,16 & 5,73 & 0,52 & 5,97 & 6,64 \\
\hline & Dez. & 0,61 & 5,80 & 5,80 & 0,50 & 6,50 & 6,50 \\
\hline \multirow{3}{*}{2012} & Jan. & 0,66 & 0,66 & 5,29 & 0,56 & 0,56 & 6,22 \\
\hline & Fev. & $-0,07$ & 0,59 & 4,59 & 0,45 & 1,01 & 5,85 \\
\hline & Mar. & 0,15 & 0,74 & 4,38 & 0,21 & 1,22 & 5,24 \\
\hline
\end{tabular}

FONTE: IPEA, FIPE, IBGE. 
Índices de Preços

\begin{tabular}{rrrrrrr}
\hline \multirow{2}{*}{ Período } & \multicolumn{3}{c}{ IGP-M } & \multicolumn{3}{c}{ IGP-DI } \\
\cline { 2 - 7 } & Mensal & No ano & $\begin{array}{r}\text { Em 12 } \\
\text { meses }\end{array}$ & Mensal & No ano & $\begin{array}{r}\text { Em 12 } \\
\text { meses }\end{array}$ \\
\hline Jan. & 0,63 & 0,63 & $-0,66$ & 1,01 & 1,01 & $-0,45$ \\
Fev. & 1,18 & 1,82 & 0,26 & 1,09 & 2,11 & 0,77 \\
Mar. & 0,94 & 2,77 & 1,95 & 0,63 & 2,75 & 2,26 \\
Abr. & 0,77 & 3,57 & 2,89 & 0,72 & 3,49 & 2,95 \\
Mai. & 1,19 & 4,80 & 4,19 & 1,57 & 5,12 & 4,38 \\
Jun. & 0,85 & 5,69 & 5,18 & 0,34 & 5,48 & 5,07 \\
Jul. & 0,15 & 5,85 & 5,79 & 0,22 & 5,71 & 5,98 \\
Ago. & 0,77 & 6,66 & 6,99 & 1,10 & 6,87 & 7,05 \\
Set. & 1,15 & 7,89 & 7,77 & 1,10 & 8,05 & 7,96 \\
Out. & 1,01 & 8,98 & 8,80 & 1,03 & 9,16 & 9,12 \\
Nov. & 1,45 & 10,56 & 10,27 & 1,58 & 10,88 & 10,76 \\
Dez. & 0,69 & 11,32 & 11,32 & 0,38 & 11,31 & 11,31 \\
\hline Jan. & 0,79 & 0,79 & 11,50 & 0,98 & 0,98 & 11,27 \\
Fev. & 1,00 & 1,80 & 11,30 & 0,96 & 1,95 & 11,13 \\
Mar. & 0,62 & 2,43 & 10,95 & 0,61 & 2,57 & 11,11 \\
Abr. & 0,45 & 2,89 & 10,60 & 0,50 & 3,08 & 10,86 \\
Mai. & 0,43 & 3,33 & 9,76 & 0,01 & 3,09 & 9,16 \\
Jun. & $-0,18$ & 3,15 & 8,64 & $-0,13$ & 2,96 & 8,65 \\
Jul. & $-0,12$ & 3,02 & 8,35 & $-0,05$ & 2,91 & 8,36 \\
Jul. & 0,44 & 3,48 & 8,00 & 0,61 & 3,54 & 7,83 \\
Ago. & 0,65 & 4,15 & 7,46 & 0,75 & 4,31 & 7,46 \\
Set. & 0,53 & 4,70 & 6,95 & 0,40 & 4,73 & 6,79 \\
Out. & 0,50 & 5,22 & 5,95 & 0,43 & 5,18 & 5,58 \\
Fev. & $-0,06$ & 0,19 & 3,44 & 0,07 & 0,37 & 3,39 \\
Mar. & 0,43 & 0,62 & 3,24 & 0,56 & 0,93 & 3,33 \\
\hline Nov. & $-0,12$ & 5,10 & 5,10 & $-0,16$ & 5,01 & 5,01 \\
Dez. & 0,25 & 0,25 & 4,53 & 0,30 & 0,30 & 4,31 \\
Jan. & & & & & &
\end{tabular}

FONTE: FGV. 
Índices de Confiança

Índice de Confiança do Consumidor (ICC)

\begin{tabular}{llllll}
\hline \multicolumn{1}{c}{ Período } & $\mathbf{2 0 0 8}$ & $\mathbf{2 0 0 9}$ & $\mathbf{2 0 1 0}$ & $\mathbf{2 0 1 1}$ & $\mathbf{2 0 1 2}$ \\
\hline $1^{\text {O Trimestre }}$ & 145,74 & 130,05 & 160,61 & 161,78 & 164,29 \\
$2^{\text {O }}$ Trimestre & 146,17 & 131,76 & 156,99 & 155,42 & \\
$3^{\text {o Trimestre }}$ & 136,52 & 146,48 & 161,43 & 153,25 & \\
$4^{\circ}$ Trimestre & 134,32 & 156,52 & 159,90 & 155,17 & \\
\hline
\end{tabular}

FONTE: IPEADATA.

Índice de Confiança do Empresário Industrial - Geral (ICEI)

\begin{tabular}{lrrrrr}
\hline Período & 2008 & $\mathbf{2 0 0 9}$ & $\mathbf{2 0 1 0}$ & $\mathbf{2 0 1 1}$ & $\mathbf{2 0 1 2}$ \\
\hline $1^{\circ}$ Trimestre & 61,8 & 47,4 & 68,1 & 61,4 & 58,0 \\
$2^{\circ}$ Trimestre & 62,0 & 49,4 & 66,4 & 58,4 & \\
$3^{\circ}$ Trimestre & 58,1 & 58,2 & 63,6 & 56,9 & \\
$4^{\circ}$ Trimestre & 52,5 & 65,9 & 62,1 & 54,9 & \\
\hline
\end{tabular}

FONTE: CNI. 


\section{Índice do Volume de Vendas Reais no Varejo ${ }^{1}$}

\begin{tabular}{|c|c|c|c|}
\hline \multicolumn{2}{|c|}{ Período } & Total $^{2}$ & $\begin{array}{l}\text { Veículos, } \\
\text { Motos, Par- } \\
\text { tes e Peças }\end{array}$ \\
\hline \multirow{12}{*}{2009} & Jan. & 143,94 & 176,10 \\
\hline & Fev. & 131,28 & 186,04 \\
\hline & Mar. & 143,93 & 185,50 \\
\hline & Abr. & 145,02 & 175,86 \\
\hline & Maio & 152,42 & 190,90 \\
\hline & Jun. & 145,72 & 229,27 \\
\hline & Jul. & 151,06 & 184,99 \\
\hline & Ago. & 153,50 & 196,97 \\
\hline & Set. & 149,52 & 234,53 \\
\hline & Out. & 161,55 & 197,13 \\
\hline & Nov. & 157,89 & 191,77 \\
\hline & Dez. & 213,24 & 192,27 \\
\hline \multirow{12}{*}{2010} & Jan. & 158,87 & 200,17 \\
\hline & Fev. & 147,30 & 215,22 \\
\hline & Mar. & 166,50 & 238,77 \\
\hline & Abr. & 158,35 & 203,18 \\
\hline & Mai. & 167,98 & 202,25 \\
\hline & Jun. & 162,27 & 211,82 \\
\hline & Jul. & 167,80 & 218,58 \\
\hline & Ago. & 169,62 & 225,39 \\
\hline & Set. & 167,41 & 227,99 \\
\hline & Out. & 175,65 & 235,45 \\
\hline & Nov. & 173,51 & 240,77 \\
\hline & Dez. & 235,08 & 242,87 \\
\hline \multirow{12}{*}{2011} & Jan. & 171,97 & 231,40 \\
\hline & Fev. & 159,78 & 235,95 \\
\hline & Mar. & 173,11 & 238,85 \\
\hline & Abr. & 174,53 & 243,50 \\
\hline & Mai. & 178,50 & 243,23 \\
\hline & Jun. & 173,75 & 241,74 \\
\hline & Jul. & 179,72 & 241,48 \\
\hline & Ago. & 180,31 & 229,65 \\
\hline & Set. & 176,08 & 233,00 \\
\hline & Out. & 183,10 & 226,19 \\
\hline & Nov. & 185,07 & 238,60 \\
\hline & Dez. & 250.81 & 246,57 \\
\hline
\end{tabular}

FONTE: IPEADATA.

NOTA: (1) Índice com ajuste sazonal.

(2) Exceto o comércio de veículos, motocicletas, partes e peças $(2003=100)$. 


\section{Contas Nacionais}

Contas Nacionais

$\mathrm{R} \$$ (milhões) do terceiro trimestre de 2010

\begin{tabular}{lrrrrrr}
\hline \multirow{2}{*}{ Período } & PIB & $\begin{array}{c}\text { Consu- } \\
\text { mo das } \\
\text { famílias }\end{array}$ & $\begin{array}{c}\text { Consu- } \\
\text { mo do } \\
\text { governo }\end{array}$ & FBKF & Export. & Import. \\
\hline 2003 & 3.106 .579 & 1.712 .632 & 755.805 & 425.447 & 354.729 & 200.222 \\
2004 & 3.284 .087 & 1.778 .064 & 786.729 & 464.243 & 408.978 & 226.860 \\
2005 & 3.387 .744 & 1.857 .490 & 804.874 & 481.074 & 447.139 & 246.075 \\
2006 & 3.521 .743 & 1.953 .998 & 825.584 & 528.087 & 469.681 & 291.473 \\
2007 & 3.736 .410 & 2.072 .660 & 867.922 & 601.229 & 498.795 & 349.401 \\
2008 & 3.929 .556 & 2.190 .179 & 895.430 & 682.831 & 501.516 & 403.057 \\
2009 & 3.916 .657 & 2.287 .450 & 923.255 & 636.922 & 455.748 & 372.432 \\
2010 & 4.211 .723 & 2.446 .301 & 962.377 & 772.804 & 508.244 & 505.899 \\
$2011 . I$ & 1.047 .667 & 626.713 & 231.397 & 192.999 & 115.684 & 124.169 \\
$2011 . I I$ & 1.091 .643 & 631.822 & 244.209 & 199.725 & 134.455 & 137.898 \\
$2011 . I I I$ & 1.096 .789 & 639.105 & 240.577 & 211.784 & 143.806 & 146.585 \\
$2011 . I V$ & 1.090 .708 & 648.829 & 264.737 & 204.728 & 137.117 & 146.566 \\
2011 & 4.326 .809 & 2.546 .470 & 980.921 & 809.237 & 531.062 & 555.219 \\
\hline
\end{tabular}

FONTE: Sistema de Contas Nacionais (IBGE).

Contas Nacionais

Variação Percentual por Período

\begin{tabular}{lrrrrrr}
\hline Periodo & PIB & $\begin{array}{c}\text { Consu- } \\
\text { mo das } \\
\text { famílias }\end{array}$ & $\begin{array}{c}\text { Consu- } \\
\text { mo do } \\
\text { governo }\end{array}$ & FBKF & Export. & Import. \\
\hline 2004 & 5,71 & 3,82 & 4,09 & 9,12 & 15,29 & 13,30 \\
2005 & 3,16 & 4,47 & 2,31 & 3,63 & 9,33 & 8,47 \\
2006 & 3,96 & 5,20 & 2,57 & 9,77 & 5,04 & 18,45 \\
2007 & 6,10 & 6,07 & 5,13 & 13,85 & 6,20 & 19,87 \\
2008 & 5,17 & 5,67 & 3,17 & 13,57 & 0,55 & 15,36 \\
2009 & $-0,33$ & 4,44 & 3,11 & $-6,72$ & $-9,13$ & $-7,60$ \\
2010 & 7,53 & 6,94 & 4,24 & 21,33 & 11,52 & 35,84 \\
$2011 . I^{*}$ & 4,24 & 6,00 & 1,85 & 8,84 & 4,00 & 13,36 \\
$2011 . I{ }^{*}$ & 3,31 & 5,62 & 3,48 & 6,19 & 6,17 & 14,78 \\
$2011 . I^{*}$ & 2,12 & 2,80 & 1,19 & 2,48 & 4,08 & 5,84 \\
$2011 . I^{*}$ & 1,37 & 2,15 & 1,26 & 1,99 & 3,71 & 6,41 \\
2011 & 2,73 & 4,09 & 1,93 & 4,71 & 4,49 & 9,75 \\
\hline
\end{tabular}

FONTE: Sistema de Contas Nacionais (IBGE).

NOTA: (*) Variação percentual sobre o mesmo período do ano anterior. 
Finanças Públicas

\begin{tabular}{lrcccc}
\hline \multicolumn{1}{c}{ Descrição } & $\mathbf{2 0 0 8}$ & $\mathbf{2 0 0 9}$ & $\mathbf{2 0 1 0}$ & $\mathbf{2 0 1 1}$ & $\mathbf{2 0 1 2}^{\text {(a) }}$ \\
\hline DLSP $^{1}$ - Total & 34,31 & 42,80 & 39,10 & 36,40 & 37,50 \\
DLSPP $^{2}$ - Externa & $-11,10$ & $-9,18$ & $-9,50$ & $-13,00$ & $-11,90$ \\
DLSP $^{3}$ - Interna & 49,89 & 50,20 & 48,70 & 49,40 & 49,50 \\
Necessidade Financ. do Set. $_{\text {Público }^{4}}$ & 5,51 & & & & \\
Superávit Primário $^{5}$ & $-3,45$ & $-2,44$ & 5,32 & 5,71 & 5,74 \\
Déficit Nominal $^{6}$ & 2,26 & 3,38 & $-2,77$ & $-3,11$ & $-5,38$ \\
FONTE $^{2}$ & & & & &
\end{tabular}

FONTE: Banco Central.

NOTA: (a) Dados contabilizados até Fevereiro de 2012.

(1) Dívida Líquida do Setor Público (\% PIB) - Tot. - Set. públ. consolidado - \% - M.

(2) Dívida Líquida do Setor Público (\% PIB) - Ext. - Set. públ. consolidado - \% - M.

(3) Dívida Líquida do Setor Público (\% PIB) - Int. - Set. públ. consolidado - \% - M.

(4) NFSP c/ desv. cambial (\% PIB) - Acumulado em 12 meses - Juros nominais -

Set. público consolidado - \%.

(5) NFSP c/ desv. cambial (\% PIB) - Acumulado em 12 meses - Resultado primário Set. público consolidado - \%.

(6) NFSP s/ desv. cambial (\% PIB) - Acumulado em 12 meses - Resultado nominal Set. público consolidado - \%.

Receitas e Despesas*

\begin{tabular}{lccccc}
\hline Descrição & $\mathbf{2 0 0 8}$ & $\mathbf{2 0 0 9}$ & $\mathbf{2 0 1 0}$ & $\mathbf{2 0 1 1}$ & $\mathbf{2 0 1 2}^{\text {(a) }}$ \\
\hline Receita Total & 716.647 & 739.304 & 919.773 & 990.406 & 180.202 \\
Receitas do Tesouro & 551.332 & 555.054 & 705.297 & 741.296 & 141.368 \\
Receita Bruta & 564.720 & 569.846 & 719.531 & 757.428 & 142.711 \\
(-) Restituições & -13.388 & -14.737 & -14.135 & -15.858 & -1.343 \\
$\quad$ (-) Incentivos Fiscais & -1 & -55 & -99 & -274 & 0 \\
Receitas da Previdência & 163.355 & 182.009 & 211.968 & 245.892 & 38.400 \\
Receitas do BCB $_{\text {Transferências }}^{1}$ & 1.745 & 2.242 & 2.508 & 3.217 & 434 \\
Receita Líquida Total $^{2}$ & 133.074 & 127.684 & 140.678 & 172.483 & 33.813 \\
Despesa Total & 537.200 & 611.621 & 779.095 & 817.922 & 146.389 \\
Pessoal e Encargos Sociais & 498.355 & 572.405 & 700.158 & 724.780 & 120.090 \\
Benefícios Previdenciários & 121.370 & 151.653 & 166.486 & 179.276 & 30.544 \\
Custeio e Capital & 164.336 & 1924.876 & 258.859 & 281.438 & 46.549 \\
Transf. do Tesouro ao & & & & & \\
BCB & $1.042,5$ & 1.180 & 1.242 & 2.135 & 345 \\
Despesas do BCB & 2.431 & 2.872 & 3.027 & 3.769 & 415 \\
\hline
\end{tabular}

FONTE: Tesouro Nacional.

NOTA: (*) em milhões de $\mathrm{R} \$$.

(a) Dados contabilizados até Fevereiro de 2012.

(1) Transferências concedidas aos Estados e Municípios.

(2) Receita Total menos Transferências. 
Atividade Industrial

\begin{tabular}{|c|c|c|c|c|c|c|}
\hline Período & $\begin{array}{c}\text { Bens de } \\
\text { capital }\end{array}$ & $\begin{array}{c}\text { Bens } \\
\text { intermedi- } \\
\text { ários } \\
\end{array}$ & $\begin{array}{c}\text { Bens de } \\
\text { cons. durá- } \\
\text { veis } \\
\end{array}$ & $\begin{array}{c}\text { Bens de } \\
\text { cons. não- } \\
\text { duráveis }\end{array}$ & $\begin{array}{l}\text { Indústria } \\
\text { de trans- } \\
\text { formacão }\end{array}$ & $\begin{array}{c}\text { Capacida- } \\
\text { de instala- } \\
\text { da }(\%)\end{array}$ \\
\hline Jan. & 158,44 & 104,20 & 118,13 & 108,22 & 97,07 & 76,70 \\
\hline Fev. & 143,90 & 101.05 & 119,43 & 107.03 & 94.34 & 77.00 \\
\hline Mar. & 141,35 & 102,70 & 136,00 & 107,82 & 110,30 & 77,10 \\
\hline Abr. & 136,89 & 104,09 & 142,82 & 108,96 & 105,71 & 77,60 \\
\hline Maio & 136,15 & 105,11 & 146,75 & 110,07 & 113,46 & 78,70 \\
\hline Jun. & 139,57 & 106,53 & 151,54 & 110,14 & 114,49 & 79,00 \\
\hline 2009 Jul. & 143,05 & 108,14 & 157,20 & 110,31 & 122,05 & 79,80 \\
\hline Ago. & 146,08 & 109,98 & 162,67 & 110,36 & 124,84 & 81,60 \\
\hline Set. & 150,74 & 112,00 & 166,36 & 110,90 & 125,40 & 82,80 \\
\hline Out. & 156,77 & 113,89 & 171,34 & 111,71 & 133,79 & 83,70 \\
\hline Nov. & 164,75 & 115,80 & 172,07 & 112,10 & 128,39 & 84.50 \\
\hline Dez. & 170.34 & 117.39 & 169.93 & 113,41 & 117.25 & 84,20 \\
\hline Jan. & 173,46 & 119,28 & 168,64 & 114,31 & 112,38 & 82,10 \\
\hline Fev. & 174,64 & 120,11 & 169,63 & 115,81 & 111,34 & 83,10 \\
\hline Mar. & 176,88 & 121,18 & 173,40 & 117,11 & 132,87 & 83,50 \\
\hline Abr. & 181,05 & 121,76 & 173,62 & 117,74 & 123,99 & 84,50 \\
\hline Maio & 184,63 & 122,61 & 173,93 & 117,42 & 130,20 & 84,60 \\
\hline Jun. & 185,26 & 122,66 & 172,39 & 116,59 & 127,27 & 85,10 \\
\hline 2010 Jul. & 183,79 & 122,80 & 170,79 & 116,08 & 132,61 & 85,00 \\
\hline Ago. & 183,05 & 122,50 & 169,41 & 115,76 & 135,48 & 85,40 \\
\hline Set. & 182,84 & 122,33 & 170,27 & 116,36 & 133,32 & 85,90 \\
\hline Out. & 182,40 & 121,85 & 172,25 & 116,71 & 135,88 & 86,40 \\
\hline Nov. & 183,95 & 122,21 & 174,33 & 118,06 & 134,92 & 86,10 \\
\hline Dez. & 184.55 & 122.45 & 175.54 & 116.36 & 119.66 & 85.30 \\
\hline Jan. & 186,43 & 122,52 & 177,18 & 116,32 & 115,08 & 83,10 \\
\hline Fev. & 187,24 & 122,82 & 178,62 & 116,36 & 119,88 & 83,70 \\
\hline Mar. & 191,97 & 123,17 & 182,95 & 117,57 & 131,42 & 83,50 \\
\hline Abr. & 192,36 & 123,31 & 178,94 & 117,69 & 121,65 & 84,00 \\
\hline Mai. & 192,45 & 123,58 & 176,22 & 118,01 & 133,37 & 84,10 \\
\hline 1 Jun. & 189,40 & 123,28 & 170,59 & 116,26 & 128,25 & 84,10 \\
\hline I Jul. & 190,98 & 123,13 & 172,99 & 116,48 & 131,78 & 84,00 \\
\hline Ago. & 192,64 & 122,29 & 172,02 & 116,17 & 138,30 & 84,00 \\
\hline Set. & 190,87 & 122,04 & 166,41 & 116,57 & 131,10 & 84,40 \\
\hline Out. & 186,37 & 121,73 & 160,24 & 115,11 & 132,62 & 84,70 \\
\hline Nov. & 181,95 & 121,59 & 155,90 & 114,94 & 130,83 & 84,50 \\
\hline Dez. & 183.77 & 121.58 & 159.99 & 115,39 & 117.85 & 84,10 \\
\hline Jan. & 177,02 & 121,80 & 161,00 & 116,77 & 112,00 & 82,10 \\
\hline 2012 Fev. & 172,11 & 120,82 & 160,18 & 117,66 & 114,62 & $\begin{array}{l}82,90 \\
82,0\end{array}$ \\
\hline
\end{tabular}

FONTE: IBGE, IPEADATA.

NOTA: Séries com ajustes sazonais (2002=100) Média Móvel Trimestral Janeiro/2010 - Fevereiro/2012, exceto Capacidade instalada. 


\section{Consumo de Energia}

Carga de energia SIN - GWh

\begin{tabular}{ccccccc}
\hline Período & $\mathbf{2 0 0 7}$ & $\mathbf{2 0 0 8}$ & $\mathbf{2 0 0 9}$ & $\mathbf{2 0 1 0}$ & $\mathbf{2 0 1 1}$ & $\mathbf{2 0 1 2}$ \\
\hline Jan. & 36590,42 & 37860,46 & 36307,74 & 40300,76 & 41973,24 & 43144,05 \\
Fev. & 33585,69 & 35930,94 & 34406,66 & 38379,57 & 39748,31 & 12828,12 \\
Mar. & 38691,68 & 38632,24 & 39112,50 & 42290,46 & 42272,70 & 46169,69 \\
Abr. & 36099,71 & 37352,08 & 35734,16 & 38530,86 & 40334,90 & \\
Maio & 36004,88 & 37167,15 & 36201,22 & 39199,79 & 40359,61 & \\
Jun. & 34410,14 & 36260,19 & 34605,66 & 37565,50 & 38493,09 & \\
Jul. & 35672,29 & 37567,80 & 36534,17 & 39173,21 & 40103,95 & \\
Ago. & 36594,24 & 38409,13 & 36909,55 & 39487,01 & 41871,28 & \\
Set. & 35897,48 & 37246,67 & 37025,88 & 39289,79 & 40575,20 & \\
Out. & 38095,16 & 39278,23 & 38431,41 & 40134,27 & 41843,00 & \\
Nov. & 36424,40 & 36594,86 & 38871,71 & 39401,42 & 40884,92 & \\
Dez. & 37618,65 & 35773,12 & 39218,90 & 41351,04 & 42811,70 & \\
\hline
\end{tabular}

FONTE: Operador Nacional do Sistema Elétrico.

Taxa de Desemprego

\begin{tabular}{|c|c|c|c|c|c|c|c|c|c|c|}
\hline \multirow{2}{*}{ Período } & \multicolumn{2}{|c|}{2008} & \multicolumn{2}{|c|}{2009} & \multicolumn{2}{|c|}{2010} & \multicolumn{2}{|c|}{2011} & \multicolumn{2}{|c|}{2012} \\
\hline & Média $^{1}$ & $\mathrm{RMC}^{2}$ & Média $^{1}$ & $\mathrm{RMC}^{2}$ & Média $^{1}$ & $\mathrm{RMC}^{2}$ & Média $^{1}$ & $\mathrm{RMC}^{2}$ & Média $^{1}$ & $\mathrm{RMC}^{2}$ \\
\hline Jan. & 8,0 & 4,8 & 8,2 & 5,4 & 7,2 & 5,4 & 6,1 & 3,5 & 5,5 & 3,8 \\
\hline Fev. & 8,7 & 5,9 & 8,5 & 6,3 & 7,4 & 5,6 & 6,4 & 4,0 & 5,7 & 3,7 \\
\hline Mar. & 8,6 & 5,8 & 9,0 & 6,3 & 7,6 & 5,5 & 6,5 & 3,8 & & \\
\hline Abr. & 8,5 & 6,3 & 8,9 & 6,1 & 7,3 & 5,0 & 6,4 & 3,7 & & \\
\hline Maio & 7,9 & 6,2 & 8,8 & 5,5 & 7,5 & 5,2 & 6,4 & 4,4 & & \\
\hline Jun. & 7,8 & 6,2 & 8,1 & 5,2 & 7,0 & 4,8 & 6,2 & 4,1 & & \\
\hline Jul. & 8,1 & 5,8 & 8,0 & 5,6 & 6,9 & 4,3 & 6,0 & 3,7 & & \\
\hline Ago. & 7,6 & 5,4 & 8,1 & 5,7 & 6,7 & 4,5 & 6,0 & 3,8 & & \\
\hline Set. & 7,6 & 4,5 & 7,7 & 5,0 & 6,2 & 3,5 & 6,0 & 3,4 & & \\
\hline Out. & 7,5 & 4,6 & 7,5 & 4,9 & 6,1 & 3,4 & 5,8 & 3,6 & & \\
\hline Nov. & 7,6 & 4,8 & 7,4 & 4,5 & 5,7 & 3,4 & 5,2 & 3,4 & & \\
\hline Dez. & 6.8 & 4.2 & 6.8 & 3.8 & 5.3 & 2.8 & 4.7 & 3.0 & & \\
\hline
\end{tabular}

FONTE: IBGE/PME; Instituto Paranaense de Desenvolvimento Econômico e Social (Ipardes). NOTA: (1) Média do índice em Recife, Salvador, Belo Horizonte, Rio de Janeiro, São Paulo e Porto Alegre.

(2) RMC - Região Metropolitana de Curitiba. 


\section{Pessoal Ocupado e Rendimentos}

\begin{tabular}{|c|c|c|c|c|}
\hline \multicolumn{2}{|c|}{ Período } & $\begin{array}{l}\text { População } \\
\text { Ocupada } \\
\text { (mil) }\end{array}$ & $\begin{array}{l}\text { Rendimento } \\
\text { Médio Real } \\
\text { (R\$) }\end{array}$ & $\begin{array}{l}\text { Massa de Rendi- } \\
\text { mento Real Efeti- } \\
\text { vo (milhões) }\end{array}$ \\
\hline \multirow{12}{*}{2009} & Jan. & 21.200 & $1.318,70$ & 31.714 \\
\hline & Fev. & 20.900 & $1.321,30$ & 31.522 \\
\hline & Mar. & 21.000 & $1.321,40$ & 31.533 \\
\hline & Abr. & 20.913 & $1.318,40$ & 31.382 \\
\hline & Maio. & 21.000 & $1.305,46$ & 31.533 \\
\hline & Jun. & 21.148 & $1.310,24$ & 31.809 \\
\hline & Jul. & 21.332 & $1.318,94$ & 32.210 \\
\hline & Ago. & 21.444 & $1.337,62$ & 32.666 \\
\hline & Set. & 21.520 & $1.338,38$ & 32.789 \\
\hline & Out. & 21.505 & $1.344,50$ & 32.965 \\
\hline & Nov. & 21.603 & $1.356,66$ & 35.245 \\
\hline & Dez. & 21.815 & $1.717,86$ & 41.116 \\
\hline \multirow{12}{*}{2010} & Jan. & 21.605 & $1.400,41$ & 33.365 \\
\hline & Fev. & 21.668 & $1.412,59$ & 33.497 \\
\hline & Mar. & 21.748 & $1.420,50$ & 33.845 \\
\hline & Abr. & 21.820 & $1.404,12$ & 33.473 \\
\hline & Maio. & 21.878 & $1.407,19$ & 33.536 \\
\hline & Jun. & 21.878 & $1.437,92$ & 34.600 \\
\hline & Jul. & 22.020 & $1.456,11$ & 35.169 \\
\hline & Ago. & 22.135 & $1.472,10$ & 36.084 \\
\hline & Set. & 22.282 & $1.499,00$ & 36.433 \\
\hline & Out. & 22.345 & $1.616,88$ & 36.401 \\
\hline & Nov. & 22.400 & $1.516,70$ & 37.744 \\
\hline & Dez. & 22.450 & $1.530,59$ & 44.662 \\
\hline \multirow{12}{*}{2011} & Jan. & 22.080 & $1.586,92$ & 35.585 \\
\hline & Fev. & 22.184 & $1.587,81$ & 35.802 \\
\hline & Mar. & 22.279 & $1.559,05$ & 35.247 \\
\hline & Abr. & 22.313 & $1.586,08$ & 35.785 \\
\hline & Mai. & 22.430 & $1.585,64$ & 35.763 \\
\hline & Jun. & 22.390 & $1.612,90$ & 36.667 \\
\hline & Jul. & 22.476 & $1.620,82$ & 37.170 \\
\hline & Ago. & 22.623 & $1.629,40$ & 36.597 \\
\hline & Set. & 22.651 & $1.612,98$ & 36.701 \\
\hline & Out. & 22.682 & $1.612,70$ & 37.825 \\
\hline & Nov. & 22.830 & $1.650,30$ & 41.329 \\
\hline & Dez. & 22.734 & $1.668,90$ & 47.438 \\
\hline \multirow{2}{*}{2012} & Jan. & 22.513 & $1.679,90$ & 38.424 \\
\hline & Fev. & 22.611 & $1.699,70$ & \\
\hline
\end{tabular}

FONTE: IBGE. 
Taxa de Juros e Reservas Internacionais

Taxa de Juros

\begin{tabular}{|c|c|c|c|}
\hline \multicolumn{2}{|c|}{ Período } & Meta Selic & $\begin{array}{c}\text { Selic efe- } \\
\text { tiva }\end{array}$ \\
\hline \multirow{12}{*}{2009} & Jan. & 13,75 & 13,66 \\
\hline & Fev. & 12,75 & 12,66 \\
\hline & Mar. & 11,25 & 11,16 \\
\hline & Abr. & 11,25 & 11,16 \\
\hline & Mai. & 10,25 & 10,16 \\
\hline & Jun. & 9,25 & 9,16 \\
\hline & Jul. & 9,25 & 9,16 \\
\hline & Ago. & 8,75 & 8,65 \\
\hline & Set. & 8,75 & 8,65 \\
\hline & Out. & 8,75 & 8,65 \\
\hline & Nov. & 8,75 & 8,65 \\
\hline & Dez. & 8,75 & 8,65 \\
\hline \multirow{12}{*}{2010} & Jan. & 8,75 & 8,65 \\
\hline & Fev. & 8,75 & 8,65 \\
\hline & Mar. & 8,75 & 8,65 \\
\hline & Abr. & 8,75 & 8,65 \\
\hline & Mai. & 9,50 & 9,40 \\
\hline & Jun. & 10,25 & 10,16 \\
\hline & Jul. & 10,25 & 10,16 \\
\hline & Ago. & 10,75 & 10,66 \\
\hline & Set. & 10,75 & 10,66 \\
\hline & Out. & 10,75 & 10,66 \\
\hline & Nov. & 10,75 & 10,66 \\
\hline & Dez. & 10,75 & 10,66 \\
\hline \multirow{12}{*}{2011} & Jan. & 10,75 & 10,66 \\
\hline & Fev. & 10,75 & 10,66 \\
\hline & Mar. & 11,25 & 11,17 \\
\hline & Abr. & 11,75 & 11,67 \\
\hline & Mai. & 11,75 & 11,67 \\
\hline & Jun. & 12,00 & 11,92 \\
\hline & Jul. & 12,25 & 12,17 \\
\hline & Ago. & 12,50 & 12,42 \\
\hline & Set. & 12,50 & 12,42 \\
\hline & Out. & 12,00 & 11,90 \\
\hline & Nov. & 11,50 & 11,40 \\
\hline & Dez. & 11,00 & 10,90 \\
\hline \multirow{3}{*}{2012} & Jan. & 10,50 & 10,40 \\
\hline & Fev. & 10,50 & \\
\hline & Mar. & 9,75 & \\
\hline
\end{tabular}

Reservas Internacionais

\begin{tabular}{|c|c|c|c|}
\hline \multicolumn{2}{|c|}{ Período } & $\begin{array}{l}\text { US\$ mi- } \\
\text { lhões }\end{array}$ & $\begin{array}{c}\text { Variação } \\
(\%)\end{array}$ \\
\hline \multirow{12}{*}{2009} & Jan. & 188.101 & $-2,93$ \\
\hline & Fev. & 186.880 & $-0,65$ \\
\hline & Mar. & 188.251 & 0,73 \\
\hline & Abr. & 190.545 & 1,22 \\
\hline & Mai. & 195.264 & 2,48 \\
\hline & Jun. & 201.467 & 3,18 \\
\hline & Jul. & 207.363 & 2,93 \\
\hline & Ago. & 215.744 & 4,04 \\
\hline & Set. & 221.629 & 2,73 \\
\hline & Out. & 231.123 & 4,28 \\
\hline & Nov. & 236.660 & 2,40 \\
\hline & Dez. & 238.520 & 0,79 \\
\hline \multirow{12}{*}{2010} & Jan. & 240.484 & 0,82 \\
\hline & Fev. & 241.033 & 0,23 \\
\hline & Mar. & 243.762 & 1,13 \\
\hline & Abr. & 247.292 & 1,45 \\
\hline & Mai. & 249.846 & 1,03 \\
\hline & Jun. & 253.114 & 1,31 \\
\hline & Jul. & 257.299 & 1,65 \\
\hline & Ago. & 261.320 & 1,56 \\
\hline & Set. & 275.206 & 5,31 \\
\hline & Out. & 284.930 & 3,53 \\
\hline & Nov. & 285.461 & 0,19 \\
\hline & Dez. & 288.575 & 1,09 \\
\hline \multirow{12}{*}{2011} & Jan. & 297.696 & 3,16 \\
\hline & Fev. & 307.516 & 3,30 \\
\hline & Mar. & 317.146 & 3,13 \\
\hline & Abr. & 328.062 & 3,44 \\
\hline & Mai. & 333.017 & 1,51 \\
\hline & Jun. & 335.775 & 0,83 \\
\hline & Jul. & 346.144 & 3,09 \\
\hline & Ago. & 353.397 & 2,10 \\
\hline & Set. & 349.708 & $-1,04$ \\
\hline & Out. & 352.928 & 0,92 \\
\hline & Nov. & 352.073 & $-0,24$ \\
\hline & Dez. & 352.012 & $-0,02$ \\
\hline \multirow{4}{*}{2012} & Jan. & 355.075 & 0,87 \\
\hline & Fev. & 356.330 & 0,35 \\
\hline & Mar. & 365.216 & 2,49 \\
\hline & Abr. & 365.285 & 0,02 \\
\hline
\end{tabular}

FONTE: Banco Central do Brasil. 
Setor Externo

\begin{tabular}{|c|c|c|c|c|c|c|}
\hline \multirow{2}{*}{\multicolumn{2}{|c|}{ Período }} & \multicolumn{3}{|c|}{ Balança Comercial } & \multicolumn{2}{|c|}{ Transações Correntes } \\
\hline & & \multirow{2}{*}{$\begin{array}{l}\begin{array}{l}\text { Expor- } \\
\text { tações } \\
\text { (FOB) }^{1}\end{array} \\
12.322\end{array}$} & \multirow{2}{*}{$\begin{array}{l}\begin{array}{l}\text { Impor- } \\
\text { tações }\end{array} \\
\text { (FOB) }^{1} \\
8.630\end{array}$} & \multirow{2}{*}{$\begin{array}{r}\text { Saldo }^{1} \\
3.692\end{array}$} & \multirow{2}{*}{$\begin{array}{r}\begin{array}{l}\text { Saldo Transa- } \\
\text { ções Correntes }\end{array} \\
89\end{array}$} & \multirow{2}{*}{$\begin{array}{c}\begin{array}{c}\text { Percentual do } \\
\text { PIB em } \mathbf{1 2} \\
\text { meses }\end{array} \\
-1.3 ?\end{array}$} \\
\hline \multirow{10}{*}{2009} & Abr. & & & & & \\
\hline & Maio & 11.985 & 9.362 & 2.623 & -1.770 & -1.42 \\
\hline & Jun. & 14.468 & 9.865 & 4.603 & -573 & -1.28 \\
\hline & Jul. & 14.142 & 11.231 & 2.911 & -1.639 & -1.25 \\
\hline & Ago. & 13.841 & 10.788 & 3.053 & -828 & -1.23 \\
\hline & Set. & 13.863 & 12.554 & 1.309 & -2.449 & -1.19 \\
\hline & Out. & 14.082 & 12.766 & 1.316 & -3.015 & -1.29 \\
\hline & Nov. & 12.653 & 12.042 & 610 & -3.271 & -1.41 \\
\hline & Dez. & 14.463 & 12.294 & 2.169 & -5.947 & -1.55 \\
\hline & Total & 152.996 & 127.723 & 25.273 & -24.334 & - \\
\hline \multirow{13}{*}{2010} & Jan. & 11.305 & 11.485 & -180 & -3.840 & $-1,52$ \\
\hline & Fev. & 12.197 & 11.808 & 389 & -3.092 & $-1,61$ \\
\hline & Mar. & 15.727 & 15.055 & 672 & -5.017 & $-1,73$ \\
\hline & Abr. & 15.161 & 13.878 & 1.283 & -4.616 & $-1,91$ \\
\hline & Maio & 17.703 & 14.248 & 3.455 & -2.008 & $-1,87$ \\
\hline & Jun. & 17.094 & 14.827 & 2.267 & -5.273 & $-2,05$ \\
\hline & Jul. & 17.673 & 16.329 & 1.344 & -4.589 & $-2,15$ \\
\hline & Ago. & 19.236 & 16.844 & 2.393 & -2.975 & $-2,23$ \\
\hline & Set. & 18.833 & 17.753 & 1.080 & -3.950 & $-2,29$ \\
\hline & Out. & 18.380 & 16.549 & 1.832 & -3.770 & $-2,32$ \\
\hline & Nov. & 17.687 & 17.396 & 292 & -4.735 & $-2,38$ \\
\hline & Dez. & 20.918 & 15.561 & 5.358 & -3.500 & $-2,27$ \\
\hline & Total & 201.915 & 181.694 & 20.221 & -47.365 & \\
\hline \multirow{13}{*}{2011} & Jan. & 15.214 & 14.802 & 412 & -5.501 & $-2,31$ \\
\hline & Fev. & 16.732 & 15.537 & 1.196 & -3.441 & $-2,30$ \\
\hline & Mar. & 19.286 & 17.736 & 1.550 & -5.639 & $-2,30$ \\
\hline & Abr. & 20.173 & 18.311 & 1.862 & -3.473 & $-2,22$ \\
\hline & Mai. & 23.209 & 19.690 & 3.519 & -4.084 & $-2,28$ \\
\hline & Jun. & 23.689 & 19.262 & 4.428 & -3.290 & $-2,17$ \\
\hline & Jul. & 22.252 & 19.117 & 3.135 & -3.493 & $-2,10$ \\
\hline & Ago. & 26.159 & 22.285 & 3.874 & -4.862 & $-2,15$ \\
\hline & Set. & 23.285 & 20.212 & 3.073 & -2.200 & $-2,05$ \\
\hline & Out. & 22.140 & 19.785 & 2.355 & -3.109 & $-2,00$ \\
\hline & Nov. & 21.773 & 21.191 & 582 & -6.673 & $-2,04$ \\
\hline & Dez. & 22.127 & 18.316 & 3.811 & -6.020 & $-2,12$ \\
\hline & Total & 256.039 & 226.244 & 29.797 & -51.785 & - \\
\hline \multirow{3}{*}{2012} & Jan. & 16.141 & 17.437 & -1.296 & -7.086 & $-2,17$ \\
\hline & Fev. & 18.028 & 16.314 & 1.714 & -1.766 & $-2,09$ \\
\hline & Mar. & 20.911 & 18.892 & 2.019 & & \\
\hline
\end{tabular}

FONTE: Banco Central do Brasil, SECEX/ MDIC.

NOTA: (1) em US\$ milhões. 
Taxa de Câmbio

\begin{tabular}{|c|c|c|c|}
\hline \multirow{2}{*}{\multicolumn{2}{|c|}{ Período }} & \multicolumn{2}{|c|}{$\begin{array}{c}\text { Taxa de câmbio real } \\
\text { efetiva }\end{array}$} \\
\hline & & IPA-OG & INPC \\
\hline \multirow{12}{*}{2009} & Jan. & 101,30 & 106,25 \\
\hline & Fev. & 99,86 & 104,09 \\
\hline & Mar. & 100,58 & 103,11 \\
\hline & Abr. & 96,70 & 98,49 \\
\hline & Maio & 91,86 & 92,91 \\
\hline & Jun. & 88,93 & 88,99 \\
\hline & Jul. & 88,53 & 87,37 \\
\hline & Ago. & 88,25 & 84,12 \\
\hline & Set. & 84,25 & 83,24 \\
\hline & Out. & 81,26 & 80,03 \\
\hline & Nov. & 81,62 & 80,05 \\
\hline & Dez. & 83,04 & 81,02 \\
\hline \multirow{12}{*}{2010} & Jan. & 83,57 & 81,61 \\
\hline & Fev. & 84,44 & 83,01 \\
\hline & Mar. & 82,45 & 80,90 \\
\hline & Abr. & 81,37 & 79,80 \\
\hline & Maio & 81,37 & 81,10 \\
\hline & Jun. & 80,58 & 80,75 \\
\hline & Jul. & 80,52 & 81,02 \\
\hline & Ago. & 79,98 & 81,90 \\
\hline & Set. & 78,03 & 80,65 \\
\hline & Out. & 78,12 & 81,06 \\
\hline & Nov. & 78,65 & 82,38 \\
\hline & Dez. & 78,16 & 81,55 \\
\hline \multirow{12}{*}{2011} & Jan. & 77,26 & 80,63 \\
\hline & Fev. & 77,92 & 81,88 \\
\hline & Mar. & & 83,17 \\
\hline & Abr. & & 81,44 \\
\hline & Mai. & & 83,72 \\
\hline & Jun. & & 83,74 \\
\hline & Jul. & & 84,16 \\
\hline & Ago. & & 87,53 \\
\hline & Set & & 95,87 \\
\hline & Out. & & 86,18 \\
\hline & Nov. & & 82,25 \\
\hline & Dez. & & 82,89 \\
\hline
\end{tabular}

FONTE: IPEA.

NOTA: Índices ponderados, base ano

$2005=100$. 


\section{Agregados Monetários}

\begin{tabular}{|c|c|c|c|c|c|}
\hline \multicolumn{2}{|c|}{ Período } & $\begin{array}{c}\text { Base } \\
\text { monetá- } \\
\text { ria* }\end{array}$ & $\mathbf{M 1}^{1}$ & $\mathbf{M}^{2}$ & $\mathbf{M}^{3}$ \\
\hline \multirow{12}{*}{2009} & Jan. & 4,50 & 6,40 & 34,70 & 62,70 \\
\hline & Fev. & 4,50 & 6,40 & 34,80 & 63,00 \\
\hline & Mar. & 4,40 & 6,30 & 34,50 & 63,00 \\
\hline & Abr. & 4,70 & 6,30 & 34,50 & 63,60 \\
\hline & Maio & 4,30 & 6,30 & 34,80 & 64,40 \\
\hline & Jun. & 4,50 & 6,50 & 35,40 & 64,90 \\
\hline & Jul. & 4,40 & 6,40 & 35,40 & 65,70 \\
\hline & Ago. & 4,40 & 6,50 & 35,40 & 66,50 \\
\hline & Set. & 4,60 & 6,70 & 35,80 & 67,50 \\
\hline & Out. & 4,70 & 6,70 & 35,50 & 67,80 \\
\hline & Nov. & 4,90 & 6,90 & 35,70 & 68,10 \\
\hline & Dez. & 5,10 & 7,70 & 36,00 & 68,10 \\
\hline \multirow{12}{*}{2010} & Jan. & 4,70 & 6,90 & 35,00 & 66,90 \\
\hline & Fev. & 4,60 & 6,80 & 34,60 & 66,30 \\
\hline & Mar. & 4,70 & 6,80 & 34,50 & 66,40 \\
\hline & Abr. & 4,50 & 6,70 & 34,00 & 65,30 \\
\hline & Mai. & 4,60 & 6,70 & 33,90 & 65,20 \\
\hline & Jun. & 4,60 & 6,70 & 34,00 & 65,20 \\
\hline & Jul. & 4,60 & 6,60 & 33,80 & 65,40 \\
\hline & Ago. & 4,80 & 6,70 & 34,10 & 65,90 \\
\hline & Set. & 4,80 & 6,80 & 34,50 & 66,70 \\
\hline & Out. & 4,80 & 6,80 & 34,30 & 66,80 \\
\hline & Nov. & 4,80 & 6,90 & 34,80 & 66,70 \\
\hline & Dez. & 5,50 & 7,50 & 36,10 & 67,60 \\
\hline \multirow{12}{*}{2011} & Jan. & 5,10 & 6,80 & 35,40 & 67,10 \\
\hline & Fev. & 4,80 & 6,60 & 35,50 & 67,80 \\
\hline & Mar. & 4,60 & 6,50 & 36,00 & 68,20 \\
\hline & Abr. & 4,40 & 6,30 & 35,80 & 68,00 \\
\hline & Mai. & 4,50 & 6,30 & 36,10 & 68,30 \\
\hline & Jun. & 4,80 & 6,40 & 36,40 & 68,40 \\
\hline & Jul. & 4,50 & 6,30 & 36,70 & 69,20 \\
\hline & Ago. & 4,40 & 6,10 & 37,00 & 70,00 \\
\hline & Set. & 4,60 & 6,30 & 37,60 & 70,70 \\
\hline & Out. & 4,60 & 6,20 & 37,50 & 70,80 \\
\hline & Nov. & 4,40 & 6,30 & 38,10 & 71,60 \\
\hline & Dez. & 5,20 & 6,90 & 39,00 & 73,10 \\
\hline \multirow{2}{*}{2012} & Jan. & 5,10 & 6,30 & 38,30 & 74,30 \\
\hline & Fev. & 4,60 & 6,20 & 38,30 & 74,90 \\
\hline
\end{tabular}

FONTE: Banco Central do Brasil.

NOTA: (*) base monetária em \% do PIB.

(1) M1- fim de período - \% PIB.

(2) M2 - fim de período - conceito novo - \% PIB.

(3) M3 - fim de período - conceito novo - \% PIB. 
